\title{
PERANCANGAN APLIKASI "NUGAS" MENGGUNAKAN METODE DESIGN THINKING DAN AGILE DEVELOPMENT
}

\author{
Rifqi Fahrudin', Reza Ilyasa ${ }^{2}$ \\ Program Studi Sistem Informasi \\ Universitas Catur Insan Cendekia \\ Jl. Kesambi 202 Kota Cirebon, Jawa Barat, Indonesia \\ rifqifhrdn@gmail.com
}

\begin{abstract}
Abstrak
Software adalah sebuah hal yang abstrak, terlebih saat dikembangkan. Ini dikarenakan sifatnya yang memang tidak memiliki wujud fisik khusus. Tugas merupakan suatu hal yang sangat dekat dengan pembelajaran dan merupakan bagian yang tidak bisa di pisahkan dalam proses pembelajaran di dunia perkuliahan. Kurangnya minat mahasiswa dalam mengerjakan tugas karna dianggap hal yang membebankan dalam proses pembelajaran. Dengan adanya UI/UX Design mempermudah developer dalam mengembangkan sebuah produk aplikasi. Salah satu metode yang sering digunakan dalam pengembangan UI/UX Design adalah Design Thinking. Design Thinking adalah adalah salah satu metode yang berkonsentrasi untuk menciptakan solusi yang diawali dengan proses empati terhadap suatu kebutuhan tertentu yang berpusat pada manusia (human centered) menuju suatu inovasi berkelanjutan berdasarkan kebutuhan penggunanya. Sedangkan untuk pembangunan aplikasi sendiri metode Agile Development adalah salah satu yang saat ini sedang marak sekali digunakan di berbagai macam startup di Indonesia. Agile Development merupakan metodologi pengembangan software yang didasarkan pada prinsip-prinsip yang sama atau pengembangan sistem jangka pendek yang memerlukan adaptasi cepat dari pengembang terhadap perubahan dalam bentuk apapun. Tujuan dari penelitian ini adalah menghasilkan sebuah aplikasi yang dapat membantu mahasiswa dalam mengelola dan mengerjakan tugas. Sehingga dalam penelitian ini metode yang digunakan adalah Design Thinking untuk pembuatan UI/UX Design dan Agile Development digunakan untuk pengembangan aplikasi.
\end{abstract}

Kata kunci: Design Thinking, Agile Development, Tugas

\begin{abstract}
Software is an abstract thing, especially when it is developed. This is because of its nature that does not have a special physical form. Assignment is something that is very close to learning and is an inseparable part of the learning process in the world of lectures. Lack of student interest in doing assignments because it is considered a burden in the learning process. With the UI/UX Design, it is easier for developers to develop an application product. One method that is often used in the development of UI/UX Design is Design Thinking. Design Thinking is a method that concentrates on creating solutions that begin with a process of empathy for a particular need that is human-centered towards a continuous innovation based on the needs of its users. As for the application development itself, the Agile Development method is one that is currently being widely used in various startups in Indonesia. Agile Development is a software development methodology based on the same principles or short-term system development that requires rapid adaptation of the developer to changes of any kind. The purpose of this research is to produce an application that can help students in managing and doing assignments. So in this study the method used is Design Thinking for making UI/UX Design and Agile Development is used for application development.
\end{abstract}

Keywords: Design Thinking, Agile Development, Task

\section{Pendahuluan}

Peningkatan pengguna smartphone di dunia salah satunya disebabkan karena aplikasi mobile yang semakin beragam. Dengan banyaknya aplikasi yang beredar, maka pengembang aplikasi mobile semakin berlomba-lomba untuk membuat aplikasi yang 
menarik, salah satunya dari sisi tampilan dan pengalaman pengguna. User Interface dan User Experience (UI/UX) memegang peran penting dalam pembangunan sebuah aplikasi, karena desain pada sebuah aplikasi harus rapi dan terorganisir. UI/UX dibangun dengan melihat kebutuhan pengguna atas sebuah aplikasi. Oleh karena itu, desain dari UI/UX menjadi salah satu daya tarik yang berpengaruh, terutama bagi sebuah aplikasi mobile (Tarute, S. Nikou, 2017)

Design Thinking sebagai acuan dalam merancang user interface aplikasi ini. Perancangan user experience dilakukan dikarenakan apabila aplikasi ini telah di implementasikan, fungsionalitas pada setiap sistem yang ada dapat berfungsi sesuai dengan apa yang dibutuhkan oleh target pengguna. Terdapat beberapa tahapan yang akan dilakukan dalam metode ini, yaitu Emphatize, Define, Ideate, Protoype, Test. Metode ini digunakan karena ingin mengutamakan adanya rancangan desain yang lebih user centered dan mudah digunakan oleh user, sehingga dapat memberikan fungsionalitas yang baik (Pangestu, T., \& Aknuranda, I. 2020).

Agile Development adalah kumpulan metodologi pengembangan aplikasi berkonsep incremental dan iterative (S. Balaji, 2012) Agile development fokus pada pengerjaan aplikasi dan komunikasi dengan klien. Tujuannya agar respon pada perubahan lebih cepat, sehingga mengurangi waktu penyelesaian proyek aplikasi. Perubahan yang dimaksud berupa biaya, requirements, jadwal, dan anggota tim (D. Greer \& Y. Hamon, 2009)

Tugas merupakan suatu hal yang sangat dekat dengan pembelajaran dan merupakan bagian yang tidak bisa di pisahkan dalam proses pembelajaran di dunia perkuliahan, tugas ada dua macam yaitu tugas individu dan tugas kelompok. Dalam mengerjakan tugas individu tugas tersebut menjadi tanggung jawab seorang sepenuhnya tetapi dalam mengerjakan tugas kelompok tanggung jawab ada di seluruh anggota kelompok (Mukti, P. 2013).

Kurangnya minat pelajar dalam mengerjakan tugas karna dianggap hal yang membebankan dalam proses pembelajaran. Sehingga penelitian ini bertujuan untuk membagun sebuah aplikasi Nugas dengan maksud untuk membantu pelajar mengolah dan mengerjakan tugas jadi hal yang lebih menyenangkan. User Interface dan User Experience (UI/UX) aplikasi Nugas akan dibangun menggunakan metode Design Thinking sedangkan untuk pengembangan akan dibangun menggunakan Agile Development. Maka dengan adanya aplikasi Nugas ini akan membantu seluruh pelajar dalam mengolah serta mengerjakan tugas yang diberikan.

\section{Tinjauan Pustaka}

\section{II.1 User Experience}

User experience adalah persepsi seseorang dan responnya dari penggunaan sebuah produk, sistem, atau jasa. User Experiece (UX) menilai seberapa kepuasan dan kenyamanan seseorang terhadap sebuah produk, sistem, dan jasa. Sebuah prinsip dalam membangun UX adalah khalayak mempunyai kekuasaan dalam menentukan tingkat kepuasan sendiri (costumer rule). Tidak hanya pada fungsionalitas pada sebuah sistem tetapi juga mempertimbakan. sasaran bisnis dan tujuan kelompok pengelolanya. Tujuan pengembangan UX adalah untuk meningkatkan kualitas pengguna yang berinteraksi, persepsi dan setiap layanan terkait produk. Persyaratan utama dalam user experience adalah memenuhi kebutuhan pengguna dengan tepat. Pengalaman tersebut dapat memiliki unsur kesederhanaan, keindahan untuk dimiliki dan digunakan. Untuk mencapai pengalaman pengguna yang bernilai tinggi maka dalam proses pembuatan harus terdapat disiplin ilmu, pemasaran, desain grafis, dan desain antarmuka (Wiryawan, M. B., 2011).

\section{II.2 User Interface}

User interface (UI) adalah suatu istilah yang digunakan untuk menggambarkan tampilan dari mesin atau komputer yang berinteraksi langsung dengan pengguna. Desain dan penyusunan tampilan antarmuka perlu diperhatikan untuk menghasilkan tampilan yang bagus (Putra, C. P., 2015).

\section{II.3 Design Thinking}

Design Thinking, metode ini dikenal sebagai suatu proses berpikir komprehensif yang berkonsentrasi untuk menciptakan solusi yang diawali dengan proses empati terhadap suatu kebutuhan tertentu yang berpusat pada manusia (human centered) menuju suatu inovasi berkelanjutan berdasarkan kebutuhan penggunanya. Dalam perkembangannya, ketiga tahapan tersebut berkembang menjadi 5 tahapan yang pada dasarnya tidak berbeda jauh namun terdapat penekanan pada 
bagian tertentu sehingga menghasilkan prosedur yang lebih terperinci (Brown, T. dan Katz, B., 2009).

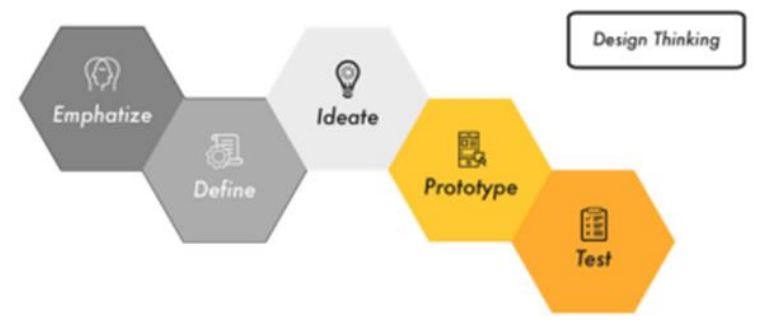

Gambar 1 Tahapan Design Thinking

Tahapan yang dilakukan dalam metode Design Thinking adalah sebagai berikut (Razi, A., 2018):

a) Emphatize (Empati) yang dianggap sebagai inti dari proses perancangan yang berpusat pada manusia (human centered design), metode ini berupaya untuk memahami pengguna dalam konteks produk yang dirancang, dengan melakukan observasi, wawancara, dan menggabungkan observasi dan wawancara dengan terlebih dahulu diberikan suatu skenario.

b) Define (Penetapan) yang merupakan proses menganalisis dan memahami berbagai wawasan yang telah diperoleh melalui empati, dengan tujuan untuk menentukan pernyataan masalah sebagai point of view atau perhatian utama pada penelitian.

c) Ideate (Ide) yang merupakan proses transisi dari rumusan masalah menuju penyelesaian masalah, adapun dalam proses ideate ini akan berkonsentrasi untuk menghasilkan gagasan atau ide sebagai landasan dalam membuat prototipe rancangan yang akan dibuat.

d) Prototype (Prototipe) dikenal sebagai rancangan awal suatu produk yang akan dibuat, untuk mendeteksi kesalahan sejak dini dan memperoleh berbagai kemungkinan baru. Dalam penerapannya, rancangan awal yang dibuat akan diujicoba kepada pengguna untuk memperoleh respon dan feedback yang sesuai untuk menyempurnakan rancangan.

e) Test (Uji coba) atau pengujian dilakukan untuk mengumpulkan berbagai feedback pengguna dari berbagai rancangan akhir yang telah dirumuskan dalam proses prototipe sebelumnya. Proses ini merupakan tahap akhir namun bersifat life cycle sehingga memungkinkan perulangan dan kembali pada tahap perancangan sebelumnya apabila terdapat kesalahan.

\section{II.4 Agile Development}

Agile Software Development juga dapat diartikan sekelompok metodologi pengembangan software yang didasarkan pada prinsip-prinsip yang sama atau pengembangan sistem jangka pendek yang memerlukan adaptasi cepat dari pengembang terhadap perubahan dalam bentuk apapun (Chandra, Y. I. 2016). Salah satu ciri dari Agile Software Development adalah tim yang tanggap terhadap perubahan karena perubahan adalah hal yang utama dalam membangun software: perubahan kebutuhan software, perubahan anggota tim, perubahan teknologi dan lain-lain. Selain itu Agile Software Development juga melihat pentingnya komunikasi antara anggota tim, antara orang-orang teknis dan businessmen, antara developer dan manajernya. Berikut adalah siklus dari Agile Development:

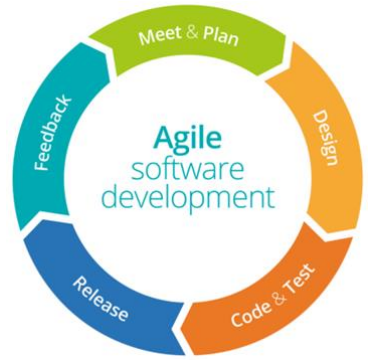

\section{Gambar 2 Agile Development Method}

a) Meet \& Plan-ning, merupakan sesi awal dari siklus agile software deveopment, dimana tempat bertemunya kedua belah sini dari 1 buah cerita, Sang Product Owner, dan Developer Team. Pada masa pertemuan ini akan terjadi pembahasan masalah dan hal-hal apa saja yang perlu dikerjakan dalam 1 siklus kedepan.

b) Design, merupakan sesi berikut yang akan menghasilkan sebuah hasil jelas yang menjadikan sebuah vision dari impian dari Dev team yang sesuai dengan kebutuhan PO dan usernya.

c) Code \& Test, proses testing merupakan proses yang sangat ditakutkan bagi majoritas mahasiswa Fasilkom pada pertama kali masuk PPW, setidaknya '16. Test-ing dimana sesi ini menentukan tujuan dan hasil dari apa yang ingin Dev team capai dalam pengembangan software pada siklus tersebut. Sedangkan Code-ing adalah masa bergeraknya kita kemenuju tujuan yang sudah di tentukan, dengan pengimplementasian component dari software 
d) Release, Setelah sukses mencapai hasil yang di inginkan, saatnya kesuksesan tersebut dibagikan kepada orang-orang disekitar. Pen-deploy-an merupakan sesi dimana hasil kerja keras dapat di periksa langsung oleh PO maupun user-user yang akan menggunakan software tersebut nantinya.

e) Feedback, masa akhir siklus atau awal siklus berikutnya, masa dimana banyak hal baru dapat dipelajari dari komentar dan masukan dari user. masamasa persiapan bertemu kembali ke dua belah sisi, atau berpisah.

\section{ANALISIS DAN PERANCANGAN}

Tahapan penelitian untuk merancang aplikasi Nugas menggunakan metode Design Thinking dan Agile Development secara umum dilihat pada Gambar 3 berikut:

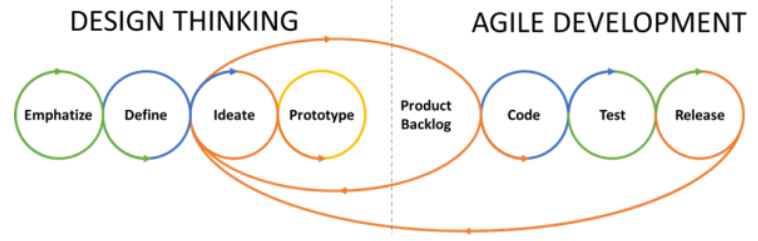

Gambar 3 Kerangka Penelitian

\section{a) Empatize}

Tahapan emphatize ini mencakup observasi, wawancara dan penyebaran kuesioner kepada calon pengguna guna mendapatkan insight fokus penelitian mengenai aplikasi Nugas. Observasi dilakukan pada bebebrapa lingkungan tempat umum dan social media, sementara wawancara dilakukan dengan beberapa pihak seperti pihak mahasiswa ataupun siswa sekolah menengah atas. Sehingga dapat dirumuskan hal yang menjadi perhatian utama dalam penelitan yang pertama ialah pelajar masih belum menemukan media yang paling efektif dalam mengelola atau mengerjakan tugas sehingga masih dibutuhkan sarana alternatif dalam membantu pelajar menerjakan tugas.

\section{b) Define}

Berdasarkan proses define didapatkan bahwa inti permasalahan utama yang dapat disimpulkan dari hasil proses empati adalah minimnya sarana yang dapat membantu pelajar dalam mengelola dan mengerjakan tugas. Sehingga solusinya adalah menghadirkan media alternatif dalam bentuk aplikasi mobile yang dirancang khusus sesuai target pengguna yang mampu memfasilitasi kebutuhan pelajar dalam pengerjaan tugas dengan memanfaatkan tekonologi internet.

c) Ideate

Ide yang akan dibuat dari tahapan define sebelumnya adalah mengenai cara menghasilkan aplikasi mobile yang mampu menjawab permasalahan minimnya sarana yang dapat membantu pelajar dalam mengelola tugas dan mengerjakan tugas.

\section{d) Prototype}

Dari proses yang dilalui dalam tahapan empati sebelumnya, didapatkan hasil kesimpulan mengenai berbagai alur kebiasaan yang dilakukan oleh pelajar saat mengalami kesulitan untuk mengerjakan tugas, sehingga perlu adanya sarana untuk membantu pelajar dalam mengerjakan tugas.

\section{e) Code}

Tahap ini adalah proses implementasi hasil prototyping kedalam code untuk menghasilkan aplikasi Nugas. Nugas merupakan aplikasi yang dibangun untuk mempermudah pelajar dalam mengelola bahkan mengerjakan tugas.

\section{f) Test}

Proses pengujian bertujuan untuk mengetahui kelemahan dari sistem yang telah dibangun. Dengan pengujian, dapat diketahui apakah sistemdapat berjalan dengan baik atau tidak dan pada aplikasi ini apakah dapat membantu para siswa dalam mengelola dan mengerjakan tugas.

\section{g) Release}

Proses sosialisasi impelemntasi aplikasi Nugas untuk pelajar dalam membantu mengelola dan mengerjakan tugas.

\section{III.1 Survey}

Kurangnya minat mahasiswa dalam mengerjakan tugas karna dianggap hal yang membebankan dalam proses pembelajaran. Hal tersebut dibuktikan melalui hasil survey in-depth interview yang dilakukan terhadap 10 responden yang terdiri dari mahasiswa Universitas Catur Insan Cendekia. 
Saya merasa kesulitan dalam mengerjakan tugas

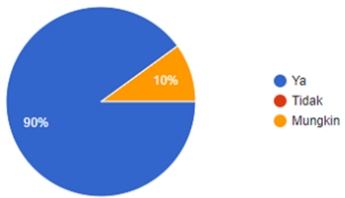

\section{Gambar 4 Hasil Survey Mahasiswa Kesulitan Dalam Mengerjakan Tugas}

Pada gambar 4, dapat disimpulkan bahwa mahasiswa memiliki kesulitan dalam mengenerjakan tugas dalam masa perkuliahan, didukung oleh $90 \%$ dari responden yang telah melakukan in-depth interview.

Saya merasa kesulitan dalam mengelola tugas

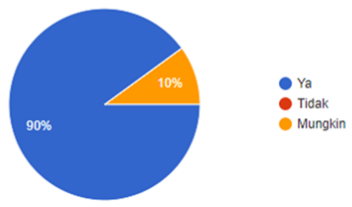

\section{Gambar 5 Hasil Survey Mahasiswa Kesulitan Dalam Mengelola Tugas}

Pada diagram 3, dapat disimpulkan bahwa mahasiswa merasa kesulitan dalam mengenerjakan tugas dalam masa perkuliahan, dikarenakan terlalu banyak tugas yang diterima didukung oleh $90 \%$ dari responden yang telah melakukan in-depth interview.

Dari hasil in-depth interview mahasiswa juga memiliki kesempatan untuk menyampaikan permasalahan khusus ketika tidak mengerjakan tugas. Berikut adalah beberapa alasan mahasiwa ketika tidak mengerjakan tugas:

\section{Tabel 1 Permasalaha Khusus Mahasiswa}

\begin{tabular}{ll}
\hline \hline Responden & Permasalahan \\
\hline \hline Responden 1 & Malas mengerjakan \\
Responden 2 & Terlalu sibuk dengan urusan lain \\
Responden 3 & Terlalu banyak tugas \\
Responden 4 & Lupa mengerjakan \\
Responden 5 & Melakukan pekerjaan lain, sehingga lupa \\
& mengerjakan tugas \\
Responden 6 & Sering lupa kalo ada tugas \\
Responden 7 & Butuh teman untuk mengerjakan tugas, agar \\
& lebih cepat selesai \\
Responden 8 & Malas mengerjakan tugas \\
Responden 9 & Lupa mengerjakan tugas \\
Responden 10 & Malas mengerjakan tugas \\
\hline \hline
\end{tabular}

Dari hasil in-depth interview terhadapa mahasiswa responden kita dapat menggambarkan
Pain Point, hal tersebut berguna untuk mendetailkan permasalahan utama yang dialami oleh setiap mahasiswa.

\section{III.2 Define}

Tujuan dari proses define ini adalah mendefinikan permasalahan yang ada pada calon pengguna aplikasi dalam hal ini adalah mahasiswa. Pada proses define juga peneliti akan membuat howmight we sebagai oportunity yang bisa kita lakukan untuk menyelesaikan masalah tersebut

\section{III.2.1 PAINT POINT}

Pain Point adalah masalah spesifik yang dialami oleh calon pelanggan dalam berbagai aspek. Secara sederhana, pain point adalah segala kesulitan yang mereka hadapi. Tujuan dari pain point ini adalah untuk meminimalisasi kesulitan pengguna akan meningkatkan kepuasan mereka saat menggunakan aplikasi dan meningkatkan kesuksesan proses bisnis.

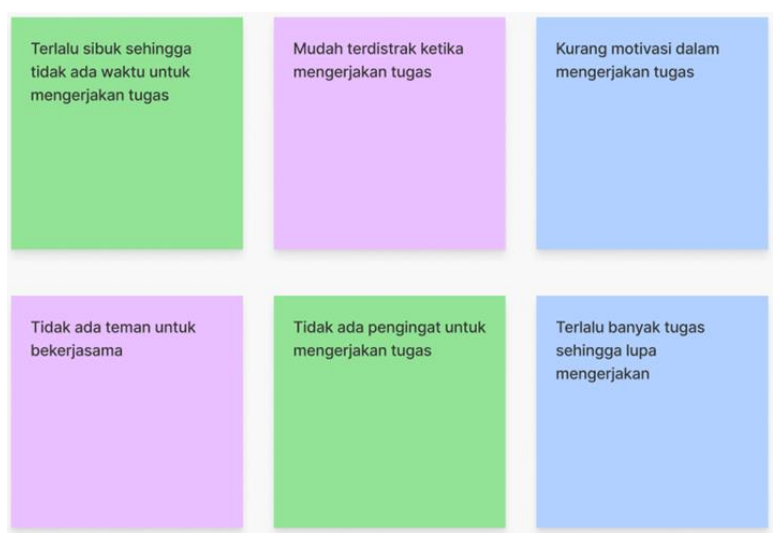

Gambar 6 Paint Point User

Gambar 6 adalah pain point yang dirasakan langsung oleh calon user ketika tidak dapat menyelesaikan tugas yang telah diberikan. Ada berbagai macam permasalahan yang ada, dalam hal ini penulisan merangkum menjadi 6 pain point.

\section{III.2.2 HOW-MIGHT WE}

Berangkat dari pain point user yang ada, target user dalam studi kasus ini adalaha mahasiswa Universitas Catur Insan Cendekia yang memiliki kesulitan dalam mengerjakan tugas. How-might we adalah pertanyaan singkat yang men-trigger brainstorming. How-might we bersumber dari pernyataan masalah atau bersumber dari prinsip desain (sebagai benih dari ide). 


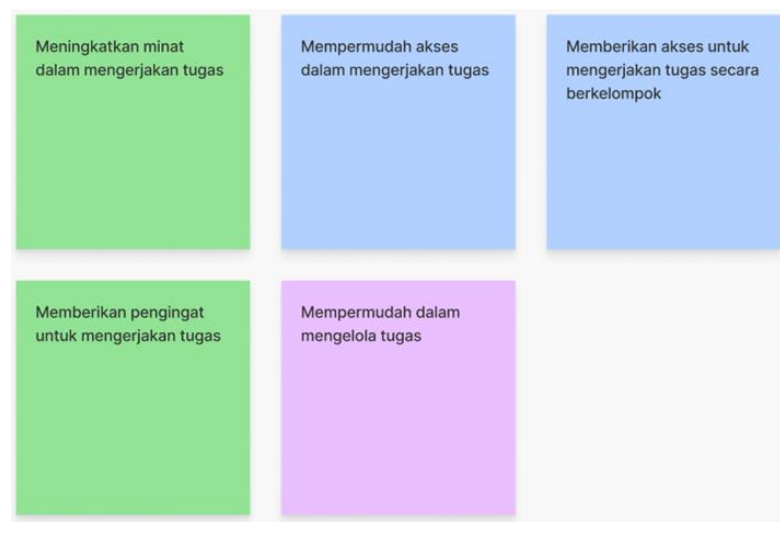

Gambar 7 How-Might We

Gambar 2 adalah how-might we sebagai benih ide yang ada berdasarkan permasalahan yang telah dijabarkan sebelumnya. Ide tersebut adalah hasil pemikiran bersama untuk menyelesaikan permasalahan yang dirasakan oleh calon pengguna dalam mengerjakan tugas.

\section{III.3 Ideate}

Dalam tahap ini berisi ide-ide untuk menemukan solusi dari permasalahan yang telah didapatkan. Proses ideate akan dilakukan dalam tiga tahapan yaitu: pembuatan solution idea, pembuatan affinity diagram dan yang terakhir adalah pembuatan crazy 8's.

\section{III.3.1 SOLUTION IDEA}

Solution idea berfungsi sebagai penentu ide-ide apa yang akan dituangkan dari permasalahan yang ada, dalam proses sebelumnya dilakukan how-might we untuk memberikan solusi yang tepat atas permasalahan tersebut. Pada tahap ini akan dipilih solusi yang tepat dari hasil how-might we, dari beberapa solusi yang sudah dituangkan peneliti melakukan voting untuk menemukan solusi utama. Terdapat dua solusi yang paling sesuai untuk menyelesaikan masalah tersebut, berikut adalah solusi yang dapat dilakukan dalam penelitian ini:

- Mempermudah dalam mengelola tugas

- Memberikan akses untuk mengerjakan tugas secara berkelompok

Kemudian dari solusi tersebut akan dibuatkan rancangan fitur-fitur apa saja yang akan disajikan dalam aplikasi untuk membermudah dalam mengelola tugas dan dapat mengerjakan tugas secara berkelompok. Berikut adalah solusi fitur-fitur yang akan dibangun dalam aplikasi nugas.
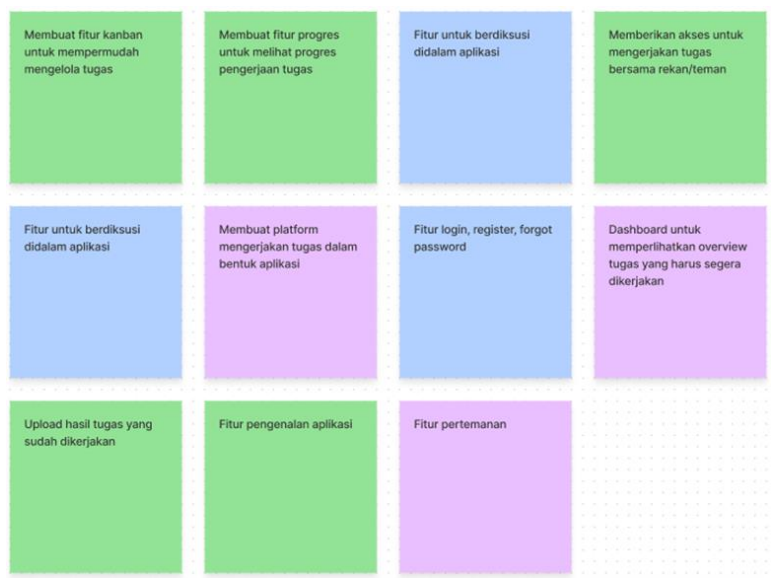

\section{Gambar 8 Fitur-Fitur Aplikasi}

Gambar 8 adalah fitur-fitur yang akan dibangun dalam aplikasi nugas, fitur-fitur tersebut adalah ideide yang muncul dari hasil dari diskusi. Terdapat 11 fitur utama yang akan dibangun dalam apalikasi nugas untuk mempermudah pengelolaan tugas dan memberikan akses mengerjakan tugas secara berkelompok.

\section{III.3.2 AFINITY DIAGRAM}

Dalam proses ini akan dilakukan pengelompokan ide-ide yang sudah dituangkan dalam proses sebelumnya menjadi beberapa kategori.
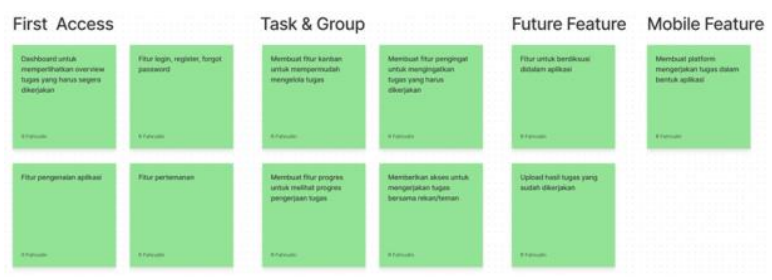

\section{Gambar 9 Afinity Diagram}

Gambar 9 adalah affinity diagram yang dibuat berdasarkan pengelompokan ide-ide yang sudah dituangkan. Pengelompokan tersebut dibagi menjadi empat kelompok, yaitu first access, task \& group, future feature dan mobile feature.

\section{III.3.3 PRIORITIZATION IDEA}

Prioritization idea bertujuan untuk memprioritaskan ide-ide yang sudah dituangkan menjadi beberapa kelompok, dalam kasus ini akan dibagi menjadi empat kelompok yaitu: yes do it now, 
do next, later dan do last. Prioritization idea ini dilakukan berdasarkan ide yang memiliki potensi besar (user value) berbanding dengan effort yang akan dikeluarkan.

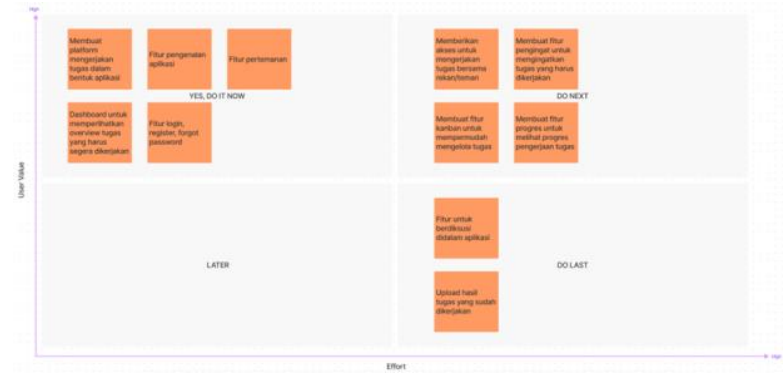

Gambar 10 Afinity Diagram

Gambar 10 adalah affinity diagram pengelompokan ide-ide berdasarkan user value dan effort. Pengelompokan ini dilakukan dengan melibatkan tim desain dan programmer.

\section{III.3.4 CRAZY 8'S}

Crazy 8's adalah membuat sketsa cepat yang menantang untuk menghasilkan delapan ide berbeda dalam delapan menit dalam bentuk sketsa. Sasarannya adalah untuk mendorong menggambarkan ide-ide yang telah ada, seringkali merupakan ide yang paling inovatif dan menghasilkan berbagai macam solusi.

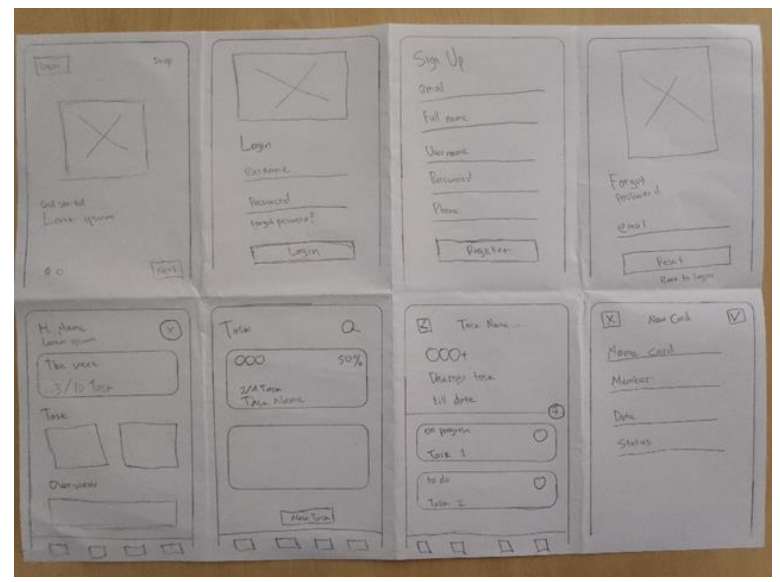

Gambar 11 Crazy 8's

Gambar 11 adalah salah satu gambar crazy 8's yang dihasilkan dari ide-ide yang udah dikumpulkan. Gambar tersebut masih berupa gambaran kasar dalam menggambarkan fitur yang akan dibuat nantinya.

\section{III.4 User Flow}

User Flow adalah diagram langkah-langkah yang harus dilakukan user untuk menyelesaikan sebuah task. User flow dibentuk sesuai dengan alur bisnis dari sebuah perusahaan, user flow ini dihasilkan dari ide-ide yang telah dibuat berdasarkan analisa permasalahan user termasuk kebiasaan user dalam menggunakan sebuah aplikasi.

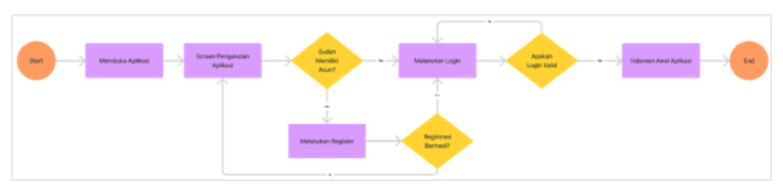

\section{Gambar 12 User Flow Login Aplikasi}

Gambar 12 adalah user flow untuk alur proses login aplikasi, dimana user akan terlebih dahulu diwajibkan melakukan login sebelum menggunakan aplikasi. Jika user belum teregistrasi, user dapat melakukan resgitrasi terlebih dahulu sebelum melakukan proses login.

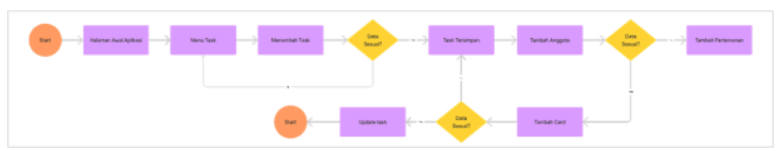

\section{Gambar 13 User Flow Pembuatan Task}

Gambar 13 adalah user flow untuk alur pembuatan task/tugas. User harus sudah melakukan login jika ingin menambahkan task. User dapat melakukan penambahan task pada menu task, user dapat menambahkan anggota untuk mengerjakan task bersama. Jika tidak ada anggota yang dapat ditambahkan, user dapat melakukan tambah pertemanan dalam menu pertemanan. User juga dapat mengupdate progress task setiap saat setelah task sudah dikerjakan.

\section{III.5 Information Architecture}

Information architecture adalah informasi yang diwujudkan dalam bentuk berupa bagan, kolom, atau desain terstruktur yang saling berkaitan dengan tujuan agar lebih mudah dimengerti oleh orang lain. Information architecture juga dapat diartikan sebagai kumpulan dari desain berupa pelabelan, pengaturan, dan pencarian serta sistem navigasi dalam website atau aplikasi. Berikut adalah gambaran information architecture untuk aplikasi yang akan di bangun. 


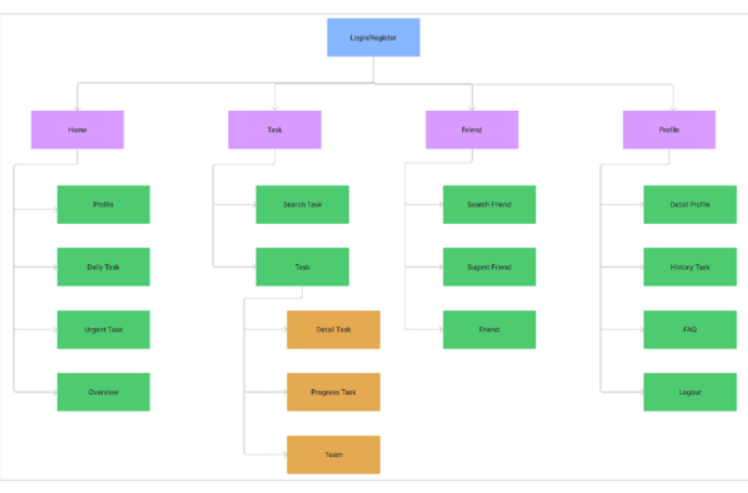

Gambar 14 Information Architecture

Gambar 14 adalah rancangan information architecture yang akan di bangun dalam aplikasi nugas. Terdapat empat menu utama yaitu menu home, menu task, menu friend dan menu profile. Dapat dilihat pada gambar 9 untuk setiap menu memiliki fungsi yang berbeda dan memiliki turunan. Menu tersebut dibuat berdasarkan ide-ide yang telah dituangkan dari proses sebelumnya.

\section{III.6 Wireframe}

Wireframe adalah sebuah kerangka untuk menata suatu item di halaman website atau aplikasi. Wireframe sendiri dapat diartikan dengan sederhana sebagai kerangka gambar. Merancang sebuah wireframe berarti merencanakan kerangka garis besar sebuah aplikasi. Berikut adalah beberapa gambaran wireframe yang telah dibuat berdasarkan hasil crazy 8 's, user flow dan information architecture yang sudah dibuat.

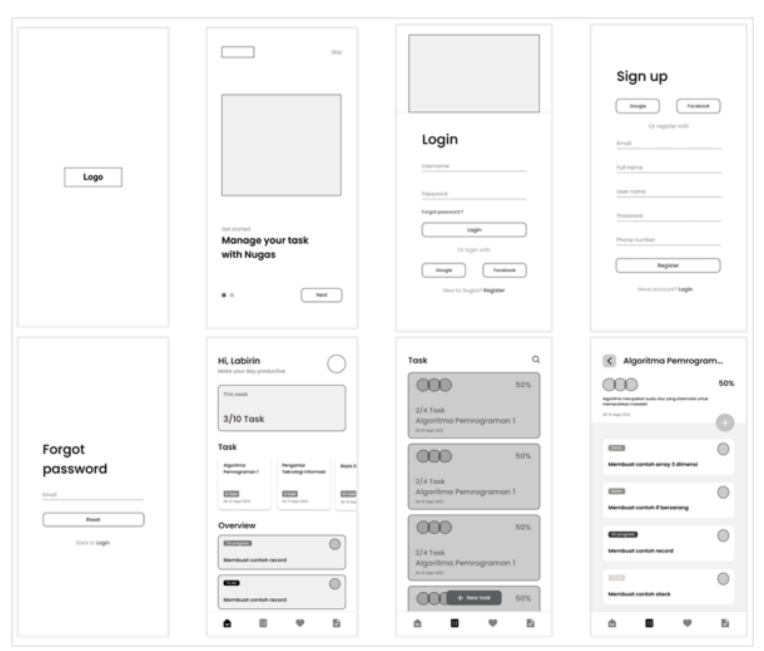

Gambar 15 Wireframe Aplikasi
Gambar 15 adalah wireframe aplikasi yang akan dibangun, terdapat beberapa contoh layout yang akan dikembangkan dalam bentuk prototype untuk lebih memperjelas user interface. Berdasarkan information architecture dalam wireframe tersebut terdapat empat menu utama yang ada dalam aplikasi yang akan dibangun.

\section{III.7 Prototype}

Prototype adalah sebuah skema rancangan sistem yang membentuk model dan standar ukuran atau skalabilitas yang akan dikerjakan nantinya. Tujuan utamanya adalah agar produk yang akan dirilis sesuai dengan permintaan user atau pasar. Berikut adalah beberapa hasil rancangan prototype yang telah dihasilkan.

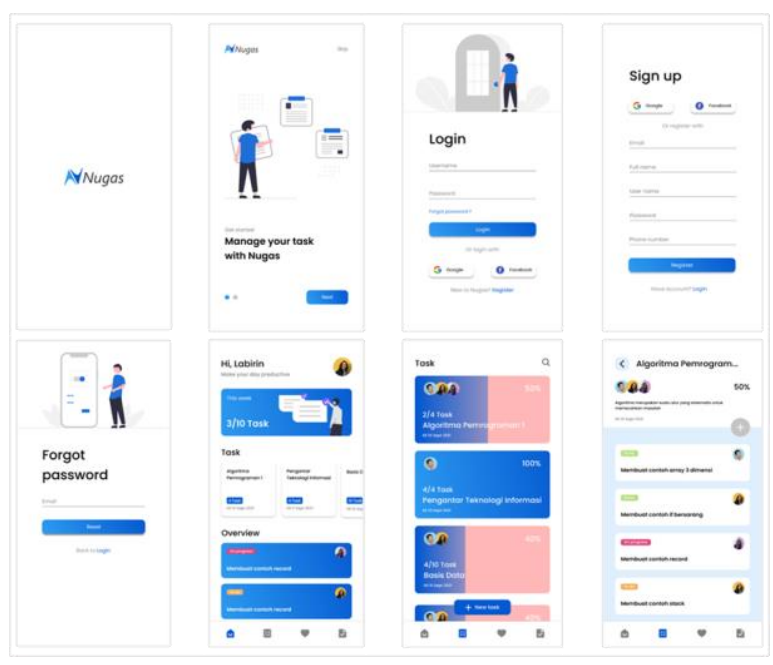

Gambar 16 Prototype Aplikasi

Gambar 16 adalah protortype aplikasi yang akan dikembangkan, terdapat beberapa fitur yang akan ada pada aplikasi tersebut. Fitur awal yang akan diakses oleh pengguna setelah melakukan login adalah halaman task, dalam halaman task terdapat beberapa informasi seperti nama pengguna, jumlah task yang sudah dan akan dikerjakan, nama task yang harus dikerjakan dan overview task yang dalam status on progress dan to do. Fitur selanjutnya adalah fitur task dimana dalam fitur tersebut terdapat semua task yang harus dikerjakan beserta detail task, jumlah task, pencarian task, team dalam task tesebut serta batas akhir pengerjaan task tersebut. Terdapat fitur lain yang tidak digambarkan dalam gambar diatas seperti fitur pertemanam dan fitur profil. 


\section{III.8 Product Backlog}

Berikut ini merupakan product backlog yang disusun berdasarkan prioritas proyek serta bersifat dinamis dengan memspesifikasi proses bisnis aplikasi yang akan dibangun. Terdapat tiga product backlog yang memiliki proritas sangat tinggi dalam pengembangan aplikasi nugas.

Tabel 2 Product Backlog

\begin{tabular}{cccc}
\hline \hline No & $\begin{array}{c}\text { Deskripsi Product } \\
\text { Backlog }\end{array}$ & Prioritas & $\begin{array}{c}\text { Estimasi } \\
\text { (Hari) }\end{array}$ \\
\hline 1 & Management User & $\begin{array}{c}\text { Sangat } \\
\text { Tinggi }\end{array}$ & 20 Hari \\
2 & Management Task & $\begin{array}{c}\text { Sangat } \\
\text { Tinggi }\end{array}$ & 30 Hari \\
3 & Management Group Task & $\begin{array}{c}\text { Sangat } \\
\text { Tinggi }\end{array}$ & 30 Hari \\
\hline \hline
\end{tabular}

Pada tabel 2 terdapat 3 prioritas product backlog yang harus dikerjakan dalam proses development/pengkodean diantaranya adalah management user dimana backlog ini akan menyelsaikan masalah yang berkaitan dengan user seperti pendaftaran, login dan pertemanan. Selanjutnya adalah management task yang berkaitan dengan task yang akan dikelola oleh user. Backlog ketiga adalah management group task yang berfungsi untuk menghubungkan antara pengguna, pertemanan dan task yang akan dapat dikerjakan secara berkelompok.

\section{III.9 Development/Code}

Dalam proses pengkodean atau tahap pembangunan aplikasi menggunakan flutter dengan bahasa pemrograman dart. Berikut adalah beberapa contoh tahap pengkodean aplikasi nugas:

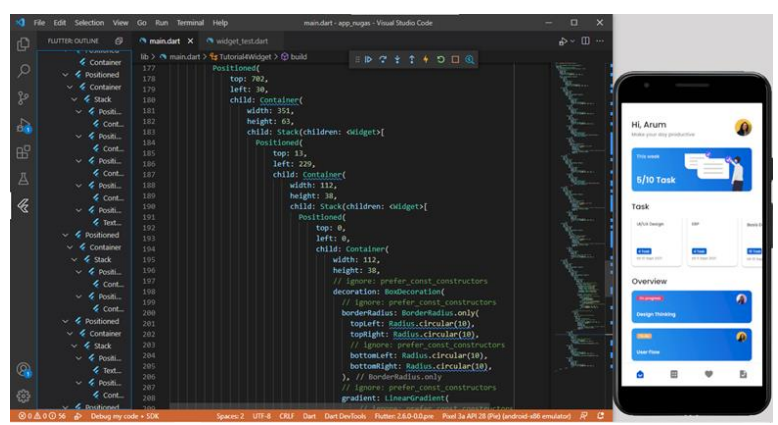

\section{Gambar 17 Pengkodean Halaman Home}

Gambar 17 adalah pengkodean untuk halaman home yang diakses setelah pengguna berhasil melakukan login. Dalam halaman tersebut terdapat beberapa informasi seperti nama pengguna, foto pengguna, jumlah task yang harus dikerjakan dalam periode minggu, urutan task yang harus segera dikerjakan dan overview detail dari progress task.

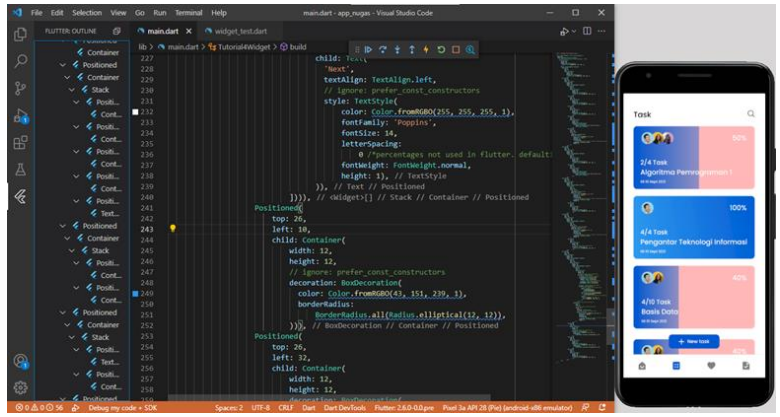

Gambar 18 Halaman Task

Gambar 18 adalah halaman task yang berisikan informasi semua task yang harus dikerjakan, dapat dilihat pada halaman tersebut dapat menampilkan progress task yang sedang dikerjakan, anggota tim yang terlibat, nama task serta waktu task tersebut harus selesai.

\section{III.10 Pengujian}

Pengujian aplikasi adalah pengujian dari aplikasi yang telah dibangun secara keseluruhan dan terintegrasi. Tujuan dari pengujian aplikasi adalah untuk mengetahui apakah aplikasi berjalan dengan baik dan sesuai dengan kebutuhan. Selain dari itu pengujian aplikasi dilakukan untuk menemmukan kesalahan dan keurangan yang ada pada aplikasi yang telah dibangun.

Tabel 3 Pengujian Aplikasi

\begin{tabular}{|c|c|c|c|}
\hline No & $\begin{array}{l}\text { Test } \\
\text { Case } \\
\end{array}$ & $\begin{array}{c}\text { Hasil Yang Di } \\
\text { Harapkan }\end{array}$ & $\begin{array}{c}\text { Hasil } \\
\text { Uji }\end{array}$ \\
\hline 1 & $\begin{array}{l}\text { Registrasi } \\
\text { Aplikasi }\end{array}$ & $\begin{array}{l}\text { Dapat masuk kehalaman } \\
\text { registrasi }\end{array}$ & Baik \\
\hline 2 & $\begin{array}{l}\text { Login } \\
\text { Aplikasi }\end{array}$ & $\begin{array}{l}\text { Dapat melakukan login } \\
\text { aplikasi setelah registrasi }\end{array}$ & Baik \\
\hline 3 & $\begin{array}{l}\text { Halaman } \\
\text { Home }\end{array}$ & $\begin{array}{l}\text { Dapat mengakses semua } \\
\text { informasi yang ada pada } \\
\text { halaman home }\end{array}$ & Baik \\
\hline 4 & $\begin{array}{l}\text { Halaman } \\
\text { Task }\end{array}$ & $\begin{array}{l}\text { Dapat mengakses halaman } \\
\text { task }\end{array}$ & Baik \\
\hline 5 & $\begin{array}{l}\text { Melakukan } \\
\text { Tambah } \\
\text { Task }\end{array}$ & $\begin{array}{l}\text { Dapat melakukan proses } \\
\text { tambah, task }\end{array}$ & Baik \\
\hline 6 & $\begin{array}{l}\text { Halaman } \\
\text { Teman }\end{array}$ & $\begin{array}{l}\text { Dapat memengakses } \\
\text { halaman teman }\end{array}$ & Baik \\
\hline 7 & $\begin{array}{l}\text { Melakukan } \\
\text { Tambah } \\
\text { teman }\end{array}$ & $\begin{array}{l}\text { Dapat melakukan Tambah } \\
\text { teman }\end{array}$ & Baik \\
\hline
\end{tabular}




\begin{tabular}{|c|c|c|c|}
\hline No & $\begin{array}{l}\text { Test } \\
\text { Case }\end{array}$ & $\begin{array}{c}\text { Hasil Yang Di } \\
\text { Harapkan }\end{array}$ & $\underset{\text { Uji }}{\text { Hasil }}$ \\
\hline 8 & $\begin{array}{l}\text { Melakukan } \\
\text { Kelola } \\
\text { Task }\end{array}$ & $\begin{array}{l}\text { Dapat } \\
\text { penambahan anggota dan } \\
\text { card untuk mengelola task }\end{array}$ & Baik \\
\hline 9 & $\begin{array}{l}\text { Melakukan } \\
\text { Update } \\
\text { Task }\end{array}$ & $\begin{array}{l}\text { Dapat mengupdate data } \\
\text { task untuk perubahan } \\
\text { progress task }\end{array}$ & Baik \\
\hline 10 & $\begin{array}{l}\text { Halaman } \\
\text { Profil }\end{array}$ & $\begin{array}{l}\text { Dapat mengakses halaman } \\
\text { profil }\end{array}$ & Baik \\
\hline 11 & $\begin{array}{l}\text { Melakukan } \\
\text { Update } \\
\text { Profil }\end{array}$ & $\begin{array}{l}\text { Dapat melakukan update } \\
\text { data profil }\end{array}$ & Baik \\
\hline 12 & $\begin{array}{l}\text { Melihat } \\
\text { History } \\
\text { Task }\end{array}$ & $\begin{array}{l}\text { Dapat mengakses halaman } \\
\text { history task yang sudah } \\
\text { selesai dikerjakan }\end{array}$ & Baik \\
\hline 13 & $\begin{array}{l}\text { Melakukan } \\
\text { Logout }\end{array}$ & $\begin{array}{l}\text { Dapat melakukan logout } \\
\text { untuk keluar dari aplikasi }\end{array}$ & Baik \\
\hline
\end{tabular}

\section{KESIMPULAN DAN SARAN}

Berdasarkan hasil pengujian, maka aplikasi telah dapat dijalankan dengan baik dan sesuai dengan kebutuhan. Dari hasil pengujian aplikasi tersebut, maka aplikasi nugas yang dibangun telah dapat dijalankan dengan baik dan sesuai dengan kebutuhan.

Saran selanjutnya adalah menambahkan fitur fitur dalam aplikasi tersebut seperti dapat melakukan diskusi terhadap tugas yang sudah dikerjakan, dapat mengupload tugas, dapat memberikan melakukan revisi tugas dan fitur - fitur lainnya yang belum tersedia.

\section{REFERENSI}

Tarute, S. Nikou, and R. Gatautis, "Mobile application driven consumer engagement," Telemat. Informatics, vol. 34, no. 4, pp. 145156, 2017.

Pangestu, T., \& Aknuranda, I. (2020). Perancangan Antarmuka Pengguna Sistem Informasi Aset Masjid Menggunakan Human Centered Design (HCD) (Studi Kasus: Masjid Ibnu Sina Jl.Veteran Malang). Jurnal Pengembangan Teknologi Informasi Dan Ilmu Komputer, 4(11), 3987-3994.

S. Balaji, "Waterfall vs v-model vs agile : A comparative study on SDLC," WATEERFALL Vs V-MODEL Vs Agil. A Comp. STUDY SDLC, vol. 2, no. 1, pp. 2630, 2012.
D. Greer and Y. Hamon, "Agile Software Development," Softw.-Pract. Exp., vol. 39, no. 7, pp. 701-36, 2009.

Mukti, P. (2013). Hubungan antara Kepercayaan Diri dan Motivasi Berprestasi dengan Social loafing pada Mahasiswa (Doctoral dissertation, Universitas Muhammadiyah Surakarta).

Wiryawan, M. B. (2011). User Experience (UX) sebagai bagian dari pemikiran desain dalam pendidikan tinggi desain komunikasi visual. Humaniora, 2(2), 1158-1166.

Putra, C. P., Sabaria, M. K., \& Widowati, S. (2015). Perancangan User Interface E-commerce Neitzo Company Menggunakana Metode Task-centered System Design. eProceedings of Engineering, 2(3).

Brown, T. dan Katz, B., 2009. Change by Design. New York: Harper Collins

Razi, A., Mutiaz, I., \& Setiawan, P. (2018). Penerapan Metode Design Thinking Pada Model Perancangan Ui/Ux Aplikasi Penanganan Laporan Kehilangan Dan Temuan Barang Tercecer.

Chandra, Y. I. (2016). Perancangan Aplikasi Resep Makanan Tradisional Indonesia Menggunakan Pendekatan Agile Process Dengan Model Extreme Programming Berbasis Android. In Seminar Nasional APTIKOM (SEMNASTIKOM) (pp. 607614).Fruhling, A., \& Lee, S. (2005). Assessing the Reliability, Validity and Adaptability of PSSUQ. 9th Americas Conference on Information Systems. Omaha, Nebraska. 